\title{
A globalização e o mercado de arte contemporânea: China
}

\author{
Amanda Mazzoni Marcato \\ DOI 10.20396/eha.vi14.3427
}

\section{Arte contemporânea e o mercado}

Trabalhar o mercado da arte é considerar toda uma rede complexa de integração entre diferentes atores. Nas últimas décadas o setor mais lucrativo do mercado de arte foi a arte contemporânea, refletindo a quantidade, diversidade e al to valor das obras comercializadas. O faturamento de leilões de obras de arte atingiu US\$14,9 bilhões em todo o ano de 2017 e o faturamento global aumentou 20\% em relação ao ano anterior (ARTPRICE, 2018).

A importância da análise econômica no que diz respeitos às artes se faz necessária, primordialmente, pelo reconhecimento dos impactos econômicos e culturais das atividades artísticas para a sociedade. Dessa forma, a opção pela análise do setor de arte contemporânea deve-se à relevância e destaque do mesmo, sob a ótica econômica e cultural.

Em um contexto de mudanças econômicas do capital global, novos protagonistas se consolidam no mercado, como o caso Chinês, alvo de estudo do presente trabalho. Segundo dados da ArtPrice, a China é hoje o principal mercado de arte do mundo, com US\$ 5,1 bilhões em faturamento: $34,2 \%$ do total mundial (ARTPRICE, 2018). O crescimento do mercado de arte chinês começa a se tornar expressivo no começo de 1994. Em 2011, três das dez obras mais caras vendidas em leilões foram de artistas chineses, além do desenvolvimento de um grande mercado de investimento de arte. (ART AND FINANCE, 2012).

O conceito de arte contemporânea não se limita a uma única definição. Dessa forma, considera-se aqui o conceito de arte contemporânea de Nathalie Heinich (2014), tradando-se de:

\footnotetext{
"um novo paradigma, que transforma completamente o mundo da arte. Equivale a um novo paradigma na história das ciências. Na arte contemporânea, a transgressão mais importante dos critérios comuns usados para definir a arte é que a obra de arte já não consiste exclusivamente no objeto proposto pelo artista, mas em todo o conjunto de operações, ações, interpretações, etc, provocadas por sua proposição. " (HEINICH, 2014).
}

1 Pós-graduanda do Programa de Pós-Graduação em Artes, Cultura e Linguagens da Universidade Federal de Juiz de Fora. 
Quando aplicada ao funcionamento do campo artístico, a teoria de Pierre Bourdieu (1989) sobre os campos sociais pode ser utilizada para explicar a maneira como as posições dos atores dentro deste campo podem estruturar as suas práticas e como estas posições podem ser hierarquizadas mediante o volume de capitais adquiridos. A teoria da dominação de Pierre Bourdieu aponta a necessidade de legitimação de uma obra por determinados valores ou cânones dominantes. Podendo ser a inovação radical uma das características da arte contemporânea, ela somente poderá ser legítima se estiver de acordo com o discurso dominante, ou se for produzido um novo discurso de legitimação pelos atores que estão nas posições dominantes. (BOURDIEU, 1989)

A partir desta necessidade de legitimação e por meio de uma perspectiva interacionista de Howard Becker (1982) a respeito do mundo da arte contemporânea, tem-se a noção de convenção em torno do valor artístico. A elaboração de reputação artística e a aquisição de um determinado estatuto num mercado de valores estão diretamente relacionadas com a construção social deste valor, com a legitimação no campo artístico e com a coordenação necessária para que isso ocorra. A cooperação e a articulação entre os atores são necessárias para conferir um determinado valor a uma obra de arte. (BECKER, 1982).

De acordo com a socióloga Raymond Moulin (2000), o mercado de arte contemporânea não funciona mais como uma justaposição de mercados nacionais que se comunicam entre si, mas sim como um mercado mundial (MOULIN, 2000). Dessa forma, a compreensão da arte contemporânea pressupõe normalmente a inserção nas redes internacionais e o reconhecimento da sua escala mundial (QUEMIN, 2001).

\section{Cultura e Globalização}

Trabalhar as questões referentes a mundialização da cultura é, portanto, de grande importância para a discussão referente ao mercado de arte contemporânea. A globalização analisa o espaço, levando em consideração que as distâncias não são mais uma condição de isolamento ou interdição para o fluxo de mercadorias, pessoas e informação. Uma das discussões que surgem a partir da temática da mundialização da cultura é se o processo da globalização se desdobra, ou não, em um processo de homogeneização cultural. Com objetivo de basear tal debate autores como Renato Ortiz, Ulf Hannerz e Arjun Appadurai serão utilizados.

Renato Ortiz (2019), ao tratar do universo do luxo e sua relação com a mundialização e cultura, postula que "a contemporaneidade é marcada por signos e símbolos desterritorializados" (OR- 
TIZ, 2019, p.7). Para Ortiz, a questão do espaço é de suma importância dentro das considerações a respeito da globalização:

"No âmbito da modernidade-mundo as categorias espaciais se transformam, por exemplo, a relação entre próximo e distante, e as fronteiras tornam-se linhas de conflitos e de afirmações de identidades. Um exemplo é o mundo do consumo, ele nos permite pensar o fenômeno da desterritorialização, ou seja, a maneira como determinados bens simbólicos afastam-se de suas raízes locais ou nacionais." (ORTIZ, 2019, p 7).

Arjun Appadurai (1990) defende que o problema central das interações no mundo é a tensão entre homogeneização e heterogeneização cultural. Segundo o autor, para um país com política de menor escala, há sempre um receio de incorporação cultural pelos países de maior escala, por meio das relações de proximidade ou de dominação. O processo de homogeneização cultural, segundo Appadurai, não considera o modo como uma tradição transforma, adapta e se apropria de elementos de uma cultura externa.

Segundo Appadurai "a complexidade da atual economia global tem algo a ver com certas disjunções fundamentais entre a economia, a cultura e a política" (APPADURAI, 1990). Dessa forma, o autor descarta a compreensão da nova economia cultural global, que "procura ser interpretada como uma ordem disjuntiva, superposta e complexa" (APPADURAI, 1990), a partir da interpretação dos modelos de centro e periferia existentes.

Ulf Hannerz (1990) admite existir atualmente uma cultura global:

"esta cultura está assinalada por um organismo de diversidade e não por uma repetição de uniformidade. Não ocorre nenhuma homogeneização de sistemas de significados e expressões [...]. No entanto, o mundo se transformou numa rede se relações sociais, e entre as suas diversas regiões existe um fluxo de significados, bem como de pessoas e de mercadorias". (HANNERZ, 1990)

Segundo o autor, essa cultura mundial é formada a partir da mistura, cada vez maior, de culturas locais diversificadas e do desenvolvimento de culturas sem suporte em nenhum território específico. Todas elas se transformam em subculturas, sendo melhor compreendidas dentro do contexto do seu ambiente cultural do que de forma isolada.

Appadurai (1990) conclui que apesar da globalização da cultura não ser o mesmo que sua homogeneidade, a mesma utiliza-se de instrumentos de homogeneização, como armamentos, técnicas de propaganda, hegemonia da linguagem, estilos de vestuário, que são consumidos na economia política e cultural local e depois repatriados como diálogos heterogêneos de soberania nacional. 
A partir desse debate e das ideias dos autores acima citados, fica cada vez mais evidente que um dos pontos mais importantes é a troca, cada vez maior, de símbolos, imagens e significados resultantes do processo de globalização, capaz de fornecer novos elementos às redes de significados das diversas culturas, sem caráter homogeneizador, mas sim, diversificador.

\section{Conclusão}

Enquanto uma arte globalizada, a arte contemporânea não reflete somente a realidade a qual se insere, já que é claro que alguns países dominam a estrutura institucional do cenário mundial. Esse controle de alguns países está distribuído em todas as instâncias do mercado da arte contemporânea, seja pelos países que mais importam obras de arte (demanda), seja pela oferta.

Até o início dos anos 1990 o mundo da arte contemporânea se pautava por critérios relativamente sólidos e consensuais, construídos entre os principais agentes de consagração do campo da arte contemporânea (artistas, historiadores, críticos, curadores e conservadores de museus, galeristas, colecionadores). A dinâmica, a consagração e os preços da arte contemporânea eram definidos no âmbito do mercado primário.

A consolidação do processo de globalização segundo Moulin (2007) e Bueno (1999) alavancou uma expansão das políticas neoliberais, reduzindo significativamente os subsídios públicos para as artes, que resultou num enfraquecimento das instâncias puramente artísticas e culturais (como museus, crítica de arte, etc) (WU, 2006). Uma decorrência foi o crescimento do capital corporativo na área, que resultou num fortalecimento das instâncias mercadológicas e do mercado secundário de leilões. O panorama atual da arte contemporânea, um cenário ainda em construção, é produto destas transformações. A expansão da arte chinesa e dos colecionadores está associada, de acordo com os especialistas (QUEMIN, 2006) a instauração de uma nova dinâmica.

Outro aspecto importante é a expansão da internet tanto na difusão da arte, quanto na incorporação dela pelo mercado, consolidando a globalização do mercado de arte, que agora se realiza no espaço mundo. 


\section{Referências Bibliográficas}

APPADURAI, Arjun. Disjunção e diferença na economia cultural global. In: FEATHERSTONE, Mike. (Org.). Cultura global: nacionalismo, globalização e modernidade. $3^{\text {a }}$ ed. Rio de Janeiro: Vozes, 1990.

ARTPRICE. Disponível em: <https://www.artprice.com/artprice-reports/the-art-market-in-2017/characteristics-ofthe-chinese-art-market-in-2017-art-market-monitor-of-artron-amma> Acesso em: 08 set 2018

ART\&FINANCE REPORT. DELOITTE. 4 a edição. 2016. Disponível em:<https://www2.deloitte.com/lu/en/pages/art-finance/articles/art-finance-report.html> . Acesso em: 08 set 2018.

BECKER, Howard S. Art Worlds. Berkeley University of California Press, 1982.

BOURDIEU, P. O poder do simbólico. Rio de Janeiro: Editora Bertrand, 1989.

BUENO, Maria Lucia. Artes Plásticas no século XX: modernidade e globalização. Editora da UNICAMP, 1999.

HANNERTZ, UIf. Cosmopolitas e locais na cultura global. In: FEATHERSTONE, Mike. (Org.). Cultura global: nacionalismo, globalização e modernidade. $3^{\text {a }}$ ed. Rio de Janeiro: Vozes, 1990.

HEINICH, Nathalie. Práticas da arte contemporânea: Uma abordagem Pragmática a Um novo Paradigma artístico. Rio de Janeiro, 2014

MOULIN, Raymonde. Le marché de l'art: mondialisation et nouvelles technologies. Paris: Flammarion, 2000.

MOULIN, Raymonde. O mercado de arte. Mundialização e novas tecnologias. Porto alegre: Zouk, 2007.

ORTIZ, Renato. Mundialização e Cultura. SP, Brasiliense, 1994.

ORTIZ, Renato. O universo do luxo. São Paulo: Alameda, 2019.

QUEMIN, A. Globalization and mixing in the visual arts: an empirical survey of "high culture" and globalization. International Sociology, v. 21, n. 4, p. 522 - 550, jul. 2006.

WU, Chin - Tao. Privatização da cultura: a intervenção corporativa nas artes desde os anos 80 . São Paulo: Boitempo, 2006. 